\title{
Consequences of Poor Power Quality - An Overview
}

\author{
Sharmistha Bhattacharyya and Sjef Cobben \\ Technical University of Eindhoven \\ The Netherlands
}

\section{Introduction}

Modern customers use large number of sensitive devices comprising of power electronics that are quite sensitive to power quality (PQ) disturbances in the supply network. From worldwide customer surveys, it is found that complaints on PQ related disturbances (for example: harmonics, voltage dips, flicker, etc.) are increasing every year. In Europe, the quality of electricity that is provided by a grid operator has to comply with reference parameters set in the European standard EN 50160 and other specific standards or the national grid codes. In contrast, it was observed that the customer's polluting loads often interact adversely with the network components and distort the network's voltage. When the supply voltage is distorted, the customer's device draws non-sinusoidal current from the network that might be different than the sinusoidal voltage condition. This can cause many technical problems (such as extra heating, misoperation, early aging of the devices etc.) to the customer's devices at his installation. The non-sinusoidal current also causes extra losses and other problems to various network components (as example: cables and transformers). Moreover, poor PQ often has large financial consequences to the affected customers (mainly to the industries with process plants). In extreme cases, poor PQ of the electric supply can cause financial losses to the network operators and the equipment manufacturers too. All these factors led to the discussion about the responsibility sharing of PQ problems in the network. In this chapter the impacts of poor PQ will be analyzed from the perspectives of the customers, the network operators and the equipment manufacturers.

\section{2. $P Q$ related complaints in different countries}

Every year the network operators in different countries around the world receive many complaints about PQ problems from different groups of customers. A customer complains when the operation of devices at his installation is interrupted leading to techno-economic inconveniences. It is observed that almost $70 \%$ of the PQ disturbances are originated at the customer's premises while 30\% are in the network side [Emanuel \& McNeil, 1997]. The Electric Power Research Institute (EPRI) conducted a five year (1990-1995) monitoring program for distribution power quality (DPQ-I) among 24 utilities throughout the United States of America. Another program DPQ-II was conducted in 2001-2002. These study results [Melhorn et al., 2005], [McNulty et al., 2002] concluded that voltage sags (dips) and swells, transient over-voltages (due to capacitor switching), harmonics and grounding 
related problems are the most common PQ complaints among the American customer as presented in Fig. 1.

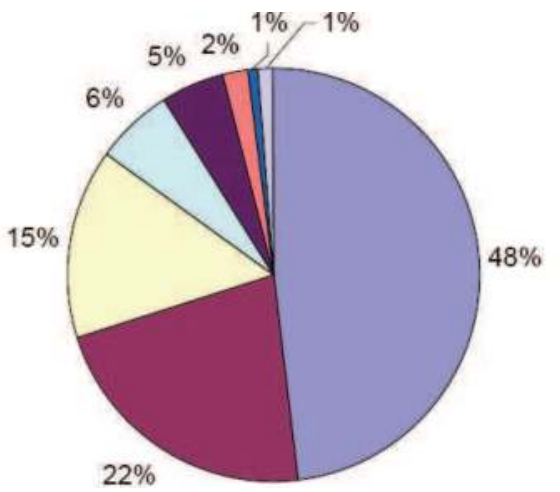

\begin{tabular}{|l|}
$\square$ Voltage Sags/Swells \\
$\square$ Harmonics \\
$\square$ Wiring/Grounding \\
$\square$ Capacitor Switching \\
$\square$ Load Interaction \\
$\square$ Other \\
$\square$ EMF/EMI \\
$\square$ Power Conditioning
\end{tabular}

Fig. 1. PQ problems experienced by the American customers

In 2001, the European Copper Institute has done a PQ survey covering 1,400 sites in 8 countries of Europe. It is found that harmonic distortions, power supply reliability, voltage dips and electromagnetic compatibility are the most important issues for the countries of the European Union (EU) [Keulenaer, 2003]. Another PQ campaign was conducted by the Leonardo Power Quality Initiative (LPQI) among various customers in the EU-25 countries in 2004. It was concluded that on average the absolute share of impacts of power quality and reliability related problems are due to voltage dips (23.6\%), short interruptions $(18.8 \%)$, long interruptions $(12.5 \%)$, harmonics $(5.4 \%)$, transients and surges $(29 \%)$ and other PQ related problems (10.7\%) [Manson \& Targosz, 2008]. In the United Kingdom, the customers mainly complain because of the disputed accounts and the supply standard related to the restoration time after fault interruptions. Some complaints are also about the supply quality issues such as voltage dips, harmonics and flicker [Wharmby, 1998]. In South Africa, voltage dips and transients have been identified as major PQ problem. This is because of the fact that a large part of the electricity infrastructure consists of overhead lines [Johnson \& Coney, 1997].

\section{Technical impacts of poor PQ}

Now-a-days the customers use large number of devices at their installations that consist of power electronics. The residential customers use different domestic appliances such as televisions (TV), video cassette recorders (VCR), microwave ovens, personal computers (PC), heating-ventilation-air conditioning equipments (HVAC), dishwashers, dryers etc. The business and office equipments include workstations, PCs, copiers, printers, lighting etc. On the other hand, the industrial customers use programmable logic controllers (PLC), automation and data processors, variable speed drives (VSD), soft starters, inverters, computerized numerical control (CNC) tools and so on. Presently, many customers use compact fluorescent lamps (CFL) for lighting their installations. Many of these devices are quite sensitive to $\mathrm{PQ}$ disturbances. Case studies and surveys in different countries around the world have been done to estimate the impacts of poor PQ to the customers. However, until now, only few cases are surveyed to analyze the technical and non-technical 
inconveniences of poor PQ to the network operators. Nevertheless, a theoretical estimation of technical losses on different network components because of various PQ disturbances can be done to get an indication of possible impacts of poor PQ in the network.

\subsection{For customers}

From various surveys, it was generally noticed that industries are vulnerable to long and short interruptions (that are considered as 'reliability issues' in the power system analysis). Voltage dip is the main PQ problem for the semiconductor and continuous manufacturing industries, and also to the hotels and telecom sectors. Harmonic problems are perceived mainly by the commercial organizations and service sectors such as banks, retail, telecom etc. Another PQ problem that draws high attention is the presence of transients and surges at the customer's installation. In 2001, the Leonardo Power Quality Initiative (LPQI) surveyed in eight countries of the European Union (EU) [Keulenaer, 2003] and declared that the customers report a complaint to the network operators when they suffer one of the inconveniences as shown in Table 1 at their sites due to poor PQ of the electric supply.

\begin{tabular}{|c|c|c|}
\hline Perceived inconvenience & Affected devices & Reported PQ problem \\
\hline $\begin{array}{c}\text { Computer lock-ups and } \\
\text { data loss }\end{array}$ & $\begin{array}{c}\text { IT equipments } \\
\text { (that are sensitive to change in } \\
\text { voltage signal) }\end{array}$ & $\begin{array}{c}\text { Presence of earth } \\
\text { leakage current causing } \\
\text { small voltage drops in } \\
\text { earth conductors }\end{array}$ \\
\hline $\begin{array}{l}\text { Loss of synchronization } \\
\text { in processing equipment }\end{array}$ & $\begin{array}{l}\text { Sensitive measurements of } \\
\text { process control equipment }\end{array}$ & $\begin{array}{l}\text { Severe harmonic } \\
\text { distortion creating } \\
\text { additional zero- } \\
\text { crossings within a cycle } \\
\text { of the sine wave. }\end{array}$ \\
\hline $\begin{array}{l}\text { Computer, electronics } \\
\text { equipments damage }\end{array}$ & $\begin{array}{l}\text { Electronic devices like computer, } \\
\text { DVD player etc. }\end{array}$ & $\begin{array}{c}\text { Lightning or a switching } \\
\text { surge }\end{array}$ \\
\hline $\begin{array}{l}\text { Lights flicker, blink or } \\
\text { dimming }\end{array}$ & $\begin{array}{l}\text { Flickering, blinking or dimming } \\
\text { of lighting devices, and other } \\
\text { visual screens }\end{array}$ & $\begin{array}{l}\text { Fast voltage changes } \\
\text { leading to visible light } \\
\text { flicker }\end{array}$ \\
\hline $\begin{array}{l}\text { Malfunctioning of motors } \\
\text { and process devices. } \\
\text { Extra heating, decreased } \\
\text { operational efficiency } \\
\text { and premature aging of } \\
\text { the equipments }\end{array}$ & Motors and process devices & $\begin{array}{c}\text { Presence of voltage and } \\
\text { current harmonics in the } \\
\text { power supply }\end{array}$ \\
\hline $\begin{array}{l}\text { Nuisance tripping of } \\
\text { protective devices }\end{array}$ & $\begin{array}{l}\text { Relays, circuit breakers and } \\
\text { contactors }\end{array}$ & $\begin{array}{c}\text { Distorted voltage } \\
\text { waveform because of } \\
\text { voltage dip }\end{array}$ \\
\hline $\begin{array}{l}\text { Noise interference to } \\
\text { telecommunication lines }\end{array}$ & Telecommunication system & $\begin{array}{l}\text { Electrical noise causing } \\
\text { interference signals }\end{array}$ \\
\hline
\end{tabular}

Table 1. Customer's reported complaints in EU-8 as per LPQI survey 
In 2008, another report was published by the LPQI in which PQ survey was conducted among the customers of the EU-25 countries [Manson \& Targosz, 2008]. It was reported that loss of synchronization of processing equipment is an acute problem in the industries (mainly for the continuous manufacturing process plants). Lock ups of computers and switching equipment tripping are the second largest problem for industries. For the service and transport sectors, circuit breaker tripping and data loss have been identified as the main problems caused by poor PQ. It was noticed that main sources of PQ disturbances in the industries are the motor driven system and static converters. In contrast, PQ problems in the service sectors are mainly originated from various electronic equipments. Fig. 2 illustrates the LPQI survey results that indicate the frequency of different PQ consequences to the industries and the service and transport sectors as a percentage of cases analyzed.

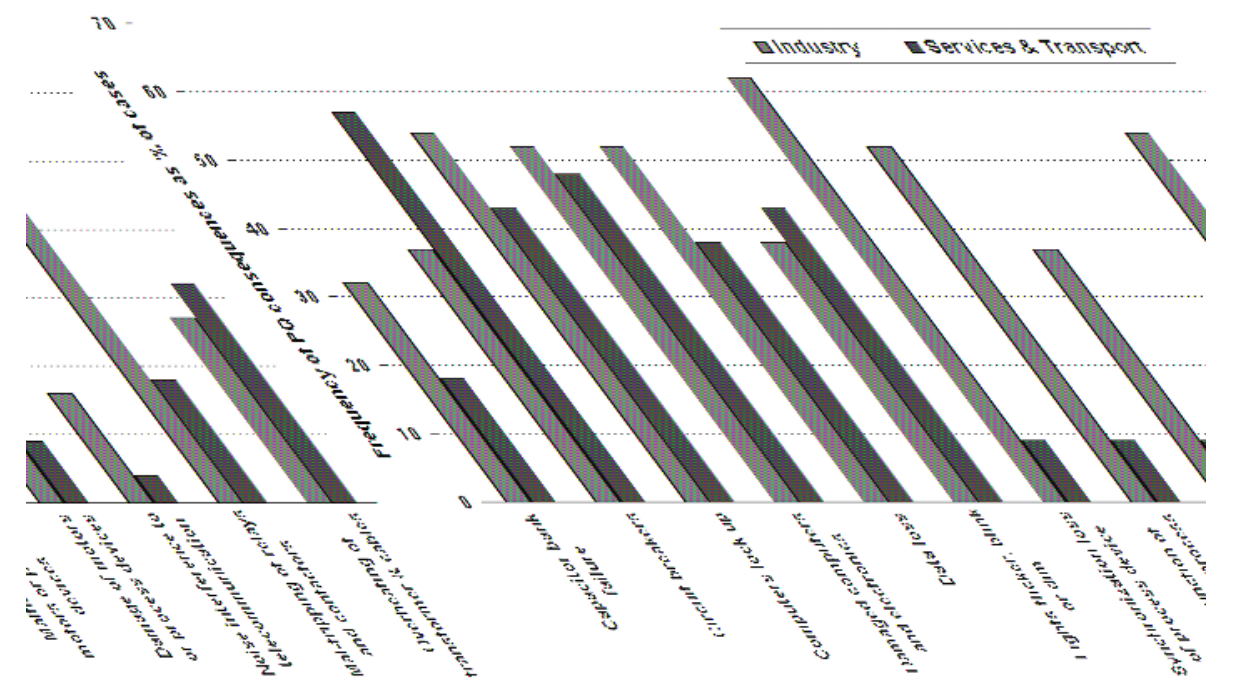

Fig. 2. Consequences of poor $P Q$ as experienced by the customers

Fig. 3 shows the survey results [Manson \& Targosz, 2008] of the devices that mostly get affected by one of the PQ problems in different installations in the EU- 25 countries. It shows that electronic equipments are the most vulnerable to PQ disturbances both in the industries as well as in the service and transport sectors.

In 2000, the EPRI and CEIDS consortium conducted a PQ survey [Lineweber \& McNulty, 2001] among the industrial customers in the USA. It was declared that the most affected devices in the industries because of poor PQ are computers and micro processor based devices (43\%), variable speed drives (13\%), lighting equipments $(8 \%)$, motors $(5 \%)$, relays $(1 \%)$ and other equipments $(30 \%)$. The 4th benchmarking report [CEER, 2008] of the European Regulators also gave an overview of PQ related costs in different countries of the world.

\subsection{For network operators}

In the last decades, customers across the globe have become more aware of PQ related disturbances at their installations. Due to large amount of PQ emissions also from the customers' sides, it is difficult for the network operator to maintain high voltage quality at a 
customer's point of connection. Moreover, a guaranteed high quality of voltage supply requires large investments in the network. Among various PQ problems, mainly harmonics in the network often interact adversely with the network components and cause inconveniences to the network operators. The operations of power electronic devices produce harmonic currents that lead to additional harmonic power flow and increase network's total apparent power demand while decrease true power factor of the network. Large harmonic current can also cause overloading and extra power losses in the network components. In extreme cases, it can lead to high thermal stresses and early ageing of the network devices. Imposing penalties to the harmonic producing customers is not presently feasible because of the lack of proper measuring devices. Harmonic currents when combined with high grid impedance increases voltage distortions in the network and in extreme situation can shift zero-crossing points of the supply voltage waveform. This increases noise and electromagnetic interference in the network. Transformers, cables and power-factor correction (PFC) capacitors are the network components that mainly get affected by PQ disturbances and are discussed briefly in the following sub-sections.

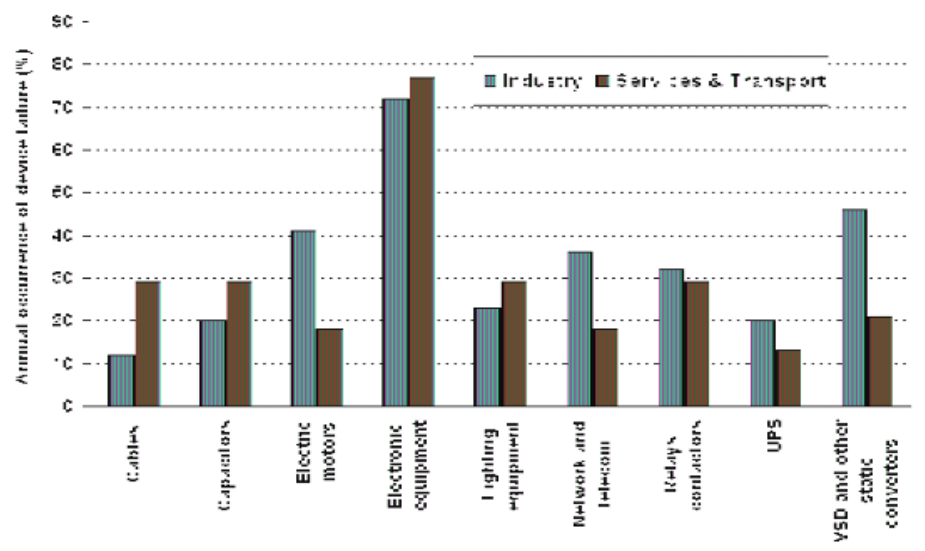

Fig. 3. Equipments affected by PQ problems in different sectors

\subsubsection{Effects on transformers}

Presence of harmonic current increases the core losses, copper losses, and stray-flux losses in a transformer. These losses consist of 'no load losses' and 'load losses'. No load loss is affected mainly by voltage harmonics, although the increase of this loss with harmonics is small. It consists of two components: hysteresis loss (due to non-linearity of the transformers) and eddy current loss (varies in proportion to the square of frequency).

The load losses of a transformer vary with the square of load current and increase sharply at high harmonic frequencies. They consist of three components:

- Resistive losses in the winding conductors and leads

- Eddy current losses in the winding conductors

- $\quad$ Eddy current losses in the tanks and structural steelwork

Eddy current losses are of large concern when harmonic current is present in the network. These losses increase approximately with the square of frequency. Total eddy current losses are normally about $10 \%$ of the losses at full load. Equation (1) gives total load losses $\left(\mathrm{P}_{\mathrm{T}}\right)$ of a transformer when harmonics are present in the network [Hulshorst \& Groeman, 2002]. 


$$
P_{T}=P_{C U} \times\left(\frac{I_{L}}{I_{1}}\right)^{2}+P_{W E 1} \times\left(\sum_{1}^{n}\left(\frac{I_{n}}{I_{1}}\right)^{2} \cdot n^{2}\right)+\left(P_{C E 1}+P_{S E 1}\right) \times\left(\sum_{1}^{n}\left(\frac{I_{n}}{I_{1}}\right)^{2} \cdot n^{0.8}\right)
$$

Where,

$$
\begin{array}{ll}
\mathrm{P}_{\mathrm{CU}} & =\text { total copper loss } \\
\mathrm{P}_{\mathrm{WE}} & =\text { eddy current losses at } 50 \mathrm{~Hz} \text { (full load) } \\
\mathrm{P}_{\mathrm{CE1}} & =\text { additional eddy current losses at } 50 \mathrm{~Hz} \text { (full load) } \\
\mathrm{P}_{\mathrm{SE1}} & \quad=\text { stray losses in construction parts at } 50 \mathrm{~Hz} \text { (full load) } \\
\mathrm{I}_{\mathrm{n}} & =\text { rms current (per unit) at harmonic ' } \mathrm{n} \text { ' } \\
\mathrm{I}_{\mathrm{L}} & =\text { total rms value of the load current (per unit) } \\
\mathrm{I}_{1} & =\text { fundamental component of load current (per unit) at } 50 \mathrm{~Hz} \text { frequency } \\
\mathrm{n} & \quad=\text { harmonic number }
\end{array}
$$

Other concern is the presence of 'triple-n' harmonics. In a network, mainly the LV nonlinear loads produce harmonics. With a MV/LV transformer of $\Delta / Y$ configuration, 'triple-n' currents circulate in the closed delta winding. Only the 'non triple-n' harmonics pass to the upstream network. When supplying non-linear loads, transformers are vulnerable to overheating. To minimize the risk of premature failure of transformers, they can either be de-rated or use as 'K-rated' transformer which are designed to operate with low losses at harmonic frequencies. Increased loading can cause overstressing of transformer and the chance of its premature failure. This effect is usually expressed in terms of 'loss of lifetime'. The hot-spot temperature is used for evaluation of a relative value for the rate of thermal ageing as shown in Fig. 4. It is taken as unity for a hot-spot temperature of $98^{\circ} \mathrm{C}$ with the assumption of an ambient temperature of $20^{\circ} \mathrm{C}$ and hot-spot temperature rise of $78^{\circ} \mathrm{C}$. Equation (2) shows the calculation of relative ageing rate (V) as a function of hot-spot temperature $\theta_{\mathrm{h}}$ [Najdenkoski et al., 2007].

$$
V=\frac{\text { Ageing rate at } \theta_{\mathrm{h}}^{\circ} \mathrm{C}}{\text { Ageing rate at } 98^{\circ} \mathrm{C}}=2^{\left(\theta_{\mathrm{h}}-98\right) / 6}
$$

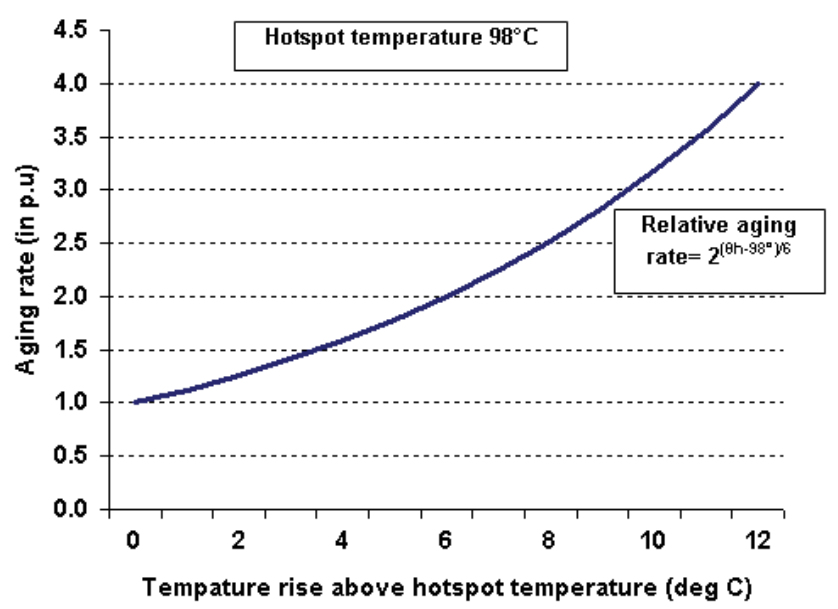

Fig. 4. Aging of a transformer with increased temperature above hotspot 


\subsubsection{Effects on cables}

Harmonic currents have two main effects on cables:

- Additional 'ohmic losses' (I2R losses) in the line and neutral conductors of a cable because of increased rms value of current due to harmonics. This causes increased operating temperatures in a cable.

- Harmonic currents along with the grid impedances cause harmonic voltages across various parts of the network. This harmonic voltage increases the dielectric stresses on the cables and can shorten their useful lifetime.

Resistance of a cable is determined by its DC value plus skin and proximity effect. The eddy current, which is generated due to the relative motion of the electromagnetic field and circulating current in a conductor, is the root cause of skin effect. The current tends to flow on the outer surface of a conductor. It increases the effective resistance of the conductor and eddy current losses, mainly at high frequencies. The 'proximity effect' is because of the mutual inductances of parallel conductors and the changing magnetic field of the nearby conductors. Both the skin effect and the proximity effect are dependent on the power system frequency, conductor size, the resistivity and the permeability of the material. The presence of harmonics in the cables influences conductor's resistance and further increases its operating temperature. This can eventually cause early aging of the cables. Heat generated in a cable consisting of ' $\mathrm{m}$ ' conductors and harmonic component ' $\mathrm{n}$ ' is given by equation (3) [Fuchs et al., 1986].

$$
Q(m)=\sum m \cdot I_{n}^{2} \cdot r_{a c}(n)
$$

Where,

$$
\begin{array}{ll}
\mathrm{Q}(\mathrm{m}) & =\text { heat generated in a cable per unit length } \\
\mathrm{m} & =\text { number of conductors in the cable } \\
\mathrm{r}_{\mathrm{ac}}(\mathrm{n}) & =\text { conductor resistance for } \mathrm{n}^{\text {th }} \text { harmonic per unit length } \\
\mathrm{I}_{\mathrm{n}} & =\text { effective or rms value of } \mathrm{n}^{\text {th }} \text { harmonic current }
\end{array}
$$

Thermal degradation of an electric device is mainly caused by temperature rise beyond the rated value. When the operating temperature deviates from the rated temperature, the life expectancy of a cable is changed and can be calculated by equation (4) [Fuchs et al., 1986].

$$
\rho=\rho_{\text {rat }} \cdot e^{-\left(\frac{E}{K}\right) \cdot \frac{\Delta \theta}{\theta_{r a t}\left(\theta_{\text {rat }}+\Delta \theta\right)}}
$$

Where,

$$
\begin{aligned}
& \rho=\text { lifetime referred to } \theta=\theta_{\text {rat }}+\Delta \theta \\
& \text { prat } \quad=\text { lifetime referred to } \theta=\theta_{\text {rat }} \\
& \Delta \theta \quad=\text { temperature rise in relation to } \theta_{\text {rat }} \text { in Celsius } \\
& \theta_{\text {rat }} \quad=\text { cable rated temperature in Kelvin } \\
& \mathrm{K}=\text { Boltzmann constant } \\
& \mathrm{E}=\text { material's activation energy }
\end{aligned}
$$

Laboratory measurement is done to identify cable's temperature rise for different loadings conditions with linear and nonlinear loads respectively. In the test, a $4 \times 2.5 \mathrm{~mm}^{2} \mathrm{XVB}-\mathrm{F} 2$ type cable with copper conductor, PVC insulation and extruded polyethylene shield is used. This is a common type installation cable in Belgium. Fixed values of set-up currents (5A, 10A, $15 \mathrm{~A}$ and $20 \mathrm{~A}$ ) are applied to the liner as well as the nonlinear loads. Incandescent lamps are used to represent linear load and PCs for nonlinear loads (that have total harmonic current 
distortion of $40 \%$ approximately). Fig. 5 (a) shows a comparison of the cable's Cu conductor temperature rise with linear and nonlinear loads for different set up currents [Desmet et al., 2004]. The ambient temperature was recorded $21^{\circ} \mathrm{C}$ at the test site. It was found that with increasing set up currents, the neutral conductor's current (because of 'triple $\mathrm{n}$ ' harmonics) increases sharply for nonlinear loads as shown in Fig. 5 (b). This increases total heat content of the cable and raises its temperature. In the test, it was noticed that the temperature of $\mathrm{Cu}$ conductor of the cable exceeded its permissible temperature limit for high nonlinear loads (while set up currents are always maintained below the limit of maximum cable current capacity). This can cause life time reduction of the cable as described in equation (4).

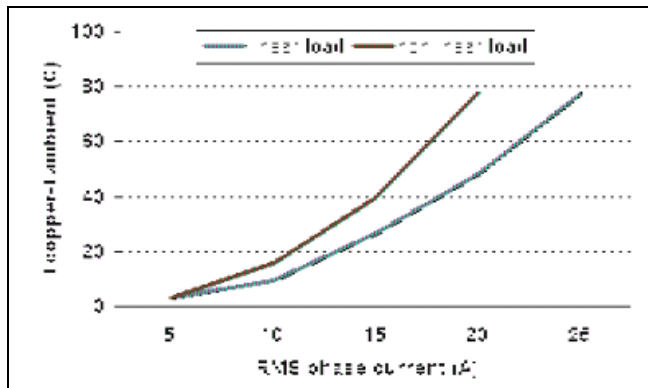

(a) Relative temperature rise of a cable's conductor with linear and nonlinear loads

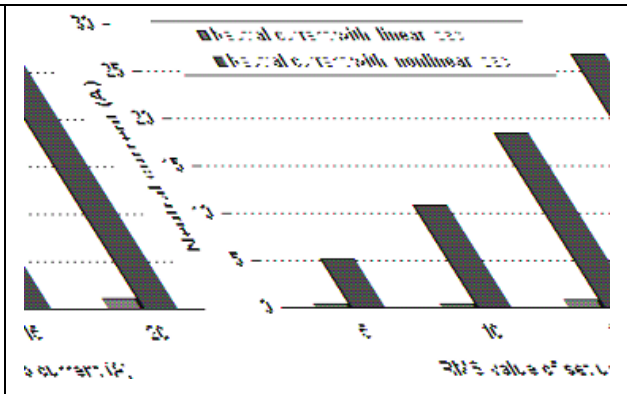

(b) Increase of neutral currents with increasing fundamental current loadings

Fig. 5. Accelerated temperature rise in a cable with nonlinear loading

\subsubsection{Effects on PFC capacitors}

Power-factor correction (PFC) capacitors are provided to draw currents with a leading phase angle to offset lagging currents drawn by the inductive loads such as an induction motor. In the presence of a non-linear load, the impedance of a PFC capacitor reduces as the frequency increases, while the source impedance is generally inductive which increases with the frequency. The presence of voltage harmonics in the power system increases the dielectric losses in the capacitors at high operating temperature and reduces the reliability. In extreme situation, harmonics in the network can cause reduction of operational life time of a PFC capacitor. The dielectric loss in a capacitor is calculated by equation (5) [Fuchs et al., 1986].

$$
P_{\text {loss }}=\sum_{n=1}^{n=40} \mathrm{C}(\tan \delta) \cdot \omega_{n} \cdot V_{n}^{2}
$$

Where,

$$
\begin{array}{ll}
\tan \delta & =\mathrm{R} /(1 / \omega \mathrm{C}) \text { is the loss factor } \\
\omega_{\mathrm{n}} & =2 \pi \mathrm{f}_{\mathrm{n}}=\text { harmonic frequency } \\
\mathrm{V} & =\text { rms voltage of } \mathrm{n}^{\text {th }} \text { harmonic }
\end{array}
$$

In the electricity networks, PFC capacitors are used to improve power factor of the network. However, with the capacitor and the stray inductance of the network components, a parallel resonant circuit can be formed. This causes very large (often localized) harmonic voltages and currents to flow, often leading to the catastrophic failure of the capacitor system. To 
reduce the chance of resonances in the network, tuned PFC capacitors can be used to filter harmonic components.

\subsection{For equipment manufacturers}

When an equipment manufacturer introduces a device in the market, he guarantees it to perform satisfactorily at sinusoidal supply voltage condition (as per the standard requirements). However, its optimum performance is not guaranteed when the supply voltage is distorted. Laboratory experiments show that devices produce higher amount of harmonic currents when the supply voltage is distorted. Table 2 compares total harmonic current distortions of some household devices under the sinusoidal and distorted supply voltage condition (with $5 \%$ total harmonic voltage distortion $\left(\mathrm{THD}_{\mathrm{v}}\right.$ ) in the network) [Bhattacharyya et al., 2010].

\begin{tabular}{|l|c|c|}
\hline \multirow{2}{*}{ Device } & \multicolumn{2}{|c|}{$\begin{array}{c}\text { Total current harmonic distortion }\left(\mathrm{THD}_{\mathrm{i}}\right) \text { with } \\
\text { respect to the total rms current drawn by the device }\end{array}$} \\
\cline { 2 - 3 } & $\begin{array}{c}\text { under clean voltage } \\
\text { condition }\end{array}$ & $\begin{array}{c}\text { under polluted voltage } \\
\text { condition }\left(\mathrm{THD}_{\mathrm{v}}=6 \%\right)\end{array}$ \\
\hline TV & $48 \%$ & $55 \%$ \\
\hline Personal computer (PC) & $87 \%$ & $89 \%$ \\
\hline Refrigerator & $10 \%$ & $18 \%$ \\
\hline Compact fluorescent lamp (CFL) & $72 \%$ & $79 \%$ \\
\hline
\end{tabular}

Table $2 . \mathrm{THD}_{\mathrm{i}}$ of devices under clean and polluted network voltage conditions

It might also happen that when specific types of devices are connected in large quantity at a certain part of the network, some orders of harmonic currents increase significantly resulting in large distortion of the network voltage. This can result in abnormal operation of other network devices. The device manufacturer, however, can not be blamed directly for such a situation as he is not responsible for his devices' operations under a distorted supply voltage condition.

A relatively new concept is developed to measure harmonic fingerprint of a device to estimate its harmonic current emission behaviour under various polluted voltage conditions. A harmonic fingerprint is a database that contains a large set of harmonic current measurements for a device at different conditions of the supply voltage. A device is tested separately for a clean sinusoidal voltage condition. Subsequently, the supply voltage is polluted with various order harmonics (from $2^{\text {nd }}$ harmonic up to $25^{\text {th }}$ harmonic order), having an amplitude variation of $1 \%$ to $10 \%$ (with a step of $1 \%$ ) and also a phase shift of $0^{\circ}$ to $360^{\circ}$ (with a step of $30^{\circ}$ ) and respective harmonic currents are measured. It is observed that with a polluted supply voltage, harmonic current emission of a device can change significantly. Reference [Cobben et al., 2007] gives more information on harmonic fingerprint development method. From a harmonic fingerprint plot, it is often possible to identify internal characteristic of a device. In Fig. 6 harmonic current emissions are plotted for a CFL when the $25^{\text {th }}$ harmonic voltage pollution is increased from $1 \%$ to $10 \%$ of the fundamental voltage for phase shifts of $0^{\circ},-30^{\circ},+30^{\circ},-180^{\circ}$, and $+150^{\circ}$ respectively [Bhattacharyya et al., 2010]. It shows that the harmonic current emission of a CFL increases almost 10 times when the $25^{\text {th }}$ harmonic voltage pollution (with $0^{\circ}$ phase shift) at the supply terminal is changed from $1 \%$ to $10 \%$ of its magnitude. 


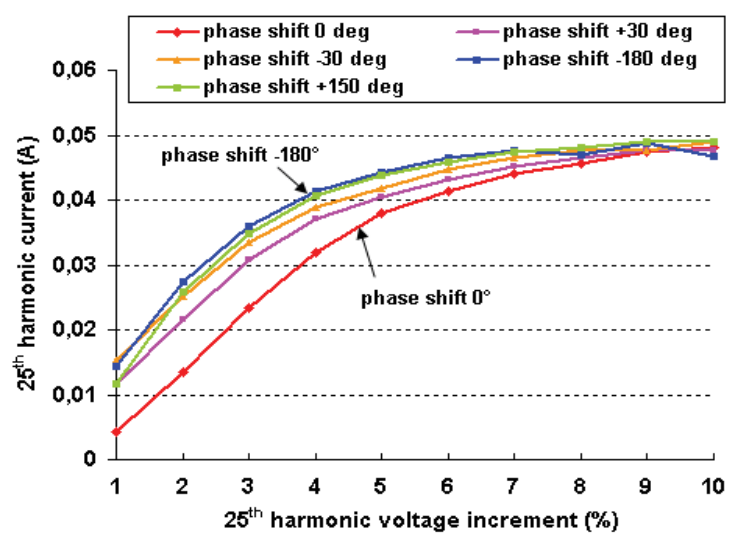

Fig. 6. Harmonic currents of a CFL for $25^{\text {th }}$ harmonic voltage pollutions

It was also found that mutual interactions occur among various harmonic-producing devices in the network. Furthermore, a distorted supply voltage (as background pollution) influences harmonic emission behaviour of the loads. Fig. 7 shows examples of a PC and a CFL when they are tested with clean sinusoidal voltage and with two polluted voltage conditions of $\mathrm{THD}_{\mathrm{v}}$ as $3.2 \%$ (marked as 'average b.g pollution') and 6\% (named as 'high b.g pollution') respectively. Harmonic current emission of a device can change significantly with the background supply voltage distortions.

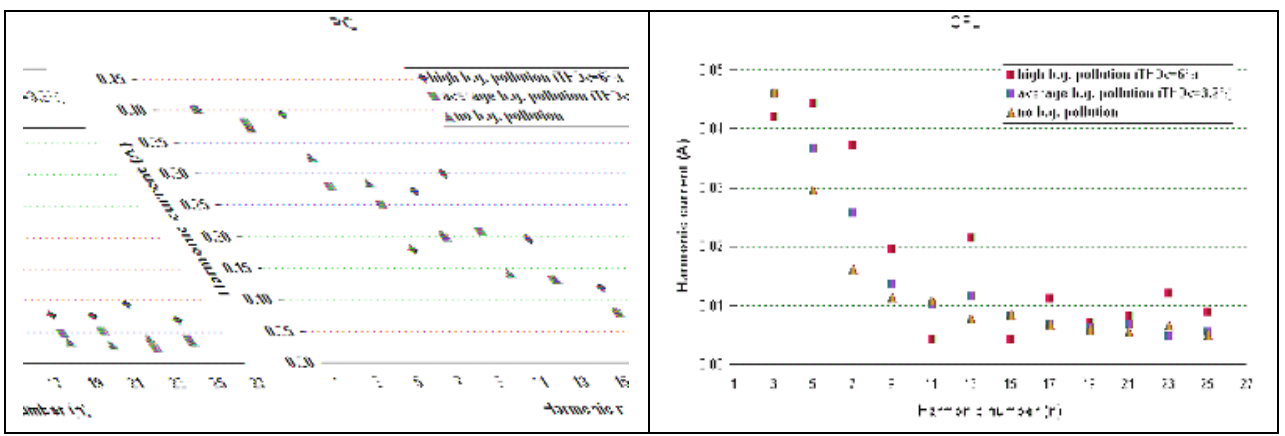

Fig. 7. Emissions of devices under background pollution conditions

\section{Financial impacts of poor $P Q$}

Power quality disturbances can have significant financial consequences to different customers and the network operators. It is quite hard to estimate correct financial losses of poor PQ as many uncertainties are involved. Therefore field surveys, interviews and case studies are carried out to get an indication of the costs of poor PQ. From literatures, many analyses are found on PQ costs for various types of customers. In contrast, very limited information is available on PQ cost for the network operators. As the cost evaluation of poor $\mathrm{PQ}$ is a complicated issue, the CIRED/CIGRE 'Joint Working Group'- JWG C4.107 was formed to develop a systematic approach for estimating various costs related to PQ 
problems. This group proposed methodologies to determine PQ costs for the customers as well as the network operators.

\subsection{For customers}

From worldwide customer surveys on the electric supply, it is found that voltage dip is one of the PQ problems that causes large inconveniences and has significant financial impacts to various industrial process equipments. The actual financial losses are customer specific and depend mainly on customer category, type and nature of activities interrupted and the customer size. Also, financial losses are event specific and different severity could incur different losses to various customers. It is noticed from different surveys that short interruptions and voltage dips are the major contributors to financial losses in terms of PQ related costs. The European Power Quality survey report declared that PQ problems cause a financial loss of more than 150 billion Euros per year in the EU-25 countries [Targosz \& Manson, 2007]. The survey was done over two years period during 2003-2004 among 62 companies from different industries and service sectors. It was found that $90 \%$ of the total financial losses are accounted to the industries. Fig. 8 shows the percentage shares of total financial losses on various PQ aspects in the EU-25 countries. It shows that $56 \%$ of total financial loss in EU-25 is a result of voltage dips and interruptions, while $28 \%$ of the costs are due to transients and surges. Other financial losses (16\%) are because of harmonics, flicker, earthing and EMC related problems.

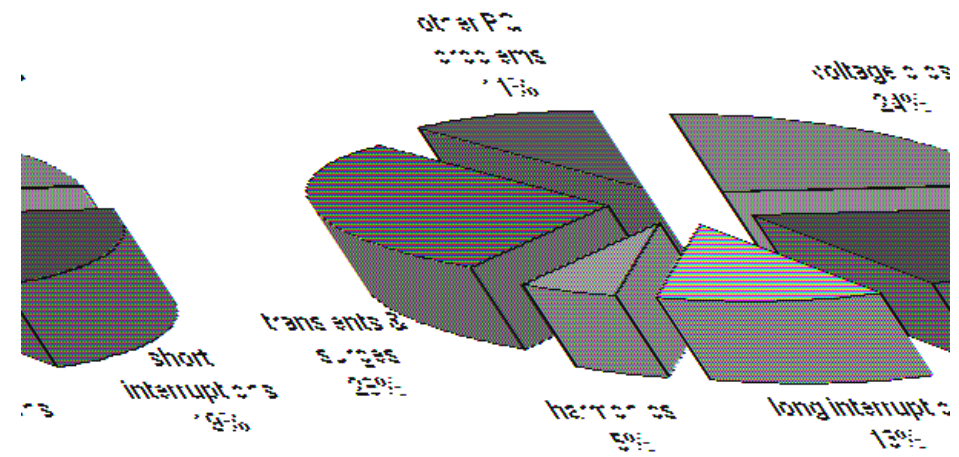

Fig. 8. Percentage share of PQ and interruption costs EU-25 countries

As per the proposal of the CIRED/CIGRE JWG 4.107 group [Targosz \& Manson, 2007], two distinct methods of measuring the economic impact of poor PQ have been identified.

- The first method is a direct method, which is an analytical approach to consider the probabilities and impacts of the events. This method leads to a precise answer, but mostly it is difficult to obtain correct input values.

- The second method is an indirect method, which considers historical data for analysis and the customer's willingness to pay for solving PQ problems.

Total cost of a PQ disturbance for a production company consists of expenditures in various accounts as follows:

- Staff cost - this is the cost because of personnel rendered unproductive for disrupted work flow. 
- Work in progress - this category includes the costs of raw material involved in production which is inevitably lost, labour costs involved in the production, extra labour needed to make up lost production etc.

- Equipment malfunctioning - if a device is affected, the consequences can be slow down of the production process, extra 'idle' time.

- Equipment damage - if an equipment is affected, consequences can be complete damage of the device, shortening of its life time, extra maintenance, need of stand-by equipment etc.

- Other costs - the costs paid for penalties due to non-delivery or late delivery, environmental fines, costs of personal injury (if any), increased insurance rate etc.

- Specific costs - this category includes extra energy bill due to harmonic pollutions produced by non-linear devices, fines for generating harmonic pollution in the network (if applicable). Reduction of personal working efficiency; related health problem due to flicker can also be included in this cost category.

- Savings - there are some savings in the production too. It includes saving from the unused materials, saving from the unpaid wages, savings on energy bill etc.

In a typical continuous manufacturing sector large financial losses are incurred by the lost work-in-progress (WIP) which is (most of the cases) about one third of total PQ costs. Also, the slowing down of processes and labour costs are quite significant in this sector. In other sectors, the situation is not very clear with the labour cost and equipment related costs. In the public services like hotels and retail sectors, PQ impact is measured as slowing down their business activities, in terms of revenue lost. In the industries the losses are mainly because of voltage dips, interruptions and transient surges. Fig. 9 shows the distribution of PQ costs in various accounts in industries and service sectors, as estimated in the LPQI survey for the EU-25 countries [Manson \& Targosz, 2008].

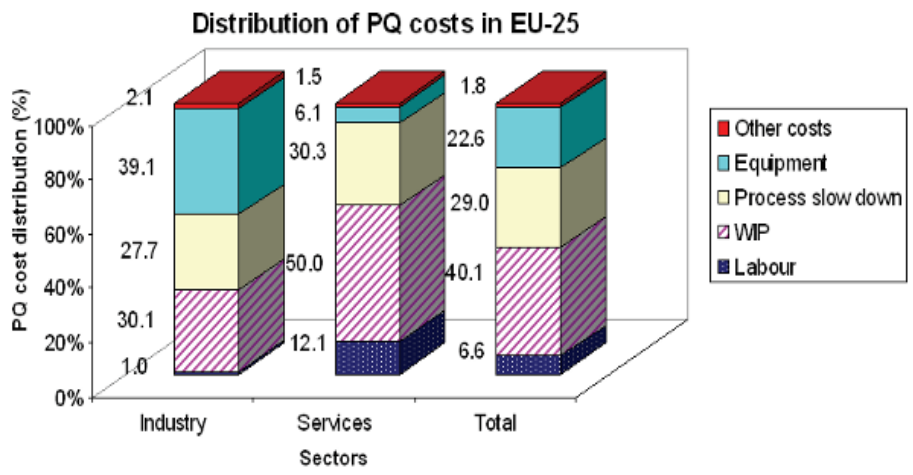

Fig. 9. PQ cost distributions per sector in EU-25

PQ cost estimation survey was also performed by the EPRI and CEIDS consortium for the American industries in 2000. It was estimated that the US economy loses annually 119 billion dollars to 188 billion dollars due to voltage dips, short interruptions and other PQ problems [Lineweber \& McNulty, 2001]. Digital economy and continuous manufacturing industries are found to be the most affected sectors. It can be remarked here that PQ cost data, obtained from different surveys, is quite difficult to compare as the references of representations in different surveys often vary. Hence, proper evaluation method of the 
analysis is required for correct interpretation of the cost data. Another report [McNulty et al., 2002] estimated the costs of momentary and 1 hour outages for various sectors in the USA. Similar type of survey was also conducted by UMIST, UK in 1992 [Kariuki \& Allan, 1996] to estimate costs of outage to different customer groups. Table 3 compares both the findings of these surveys. It shows that outage costs in different sectors in UK and US vary significantly, except for the industrial customers suffering momentary outages.

\begin{tabular}{|l|c|c|c|c|}
\hline \multirow{2}{*}{ Sector } & \multicolumn{2}{|c|}{$\begin{array}{c}\text { Survey done for UK customers } \\
\text { Costs per outage per customer } \\
(€ / \text { event/customer })^{1}\end{array}$} & \multicolumn{2}{|c|}{$\begin{array}{c}\text { Survey done for US customers } \\
\text { Costs per outage per customer } \\
(€ / \text { event/customer })^{2}\end{array}$} \\
\cline { 2 - 5 } & momentary & 1 hour & momentary & 1 hour \\
\hline Residential & - & 0.84 & 1.63 & 2.02 \\
\hline Commercial & 13.8 & 127.2 & 454 & 664 \\
\hline Industrial & 1440 & 5160 & 1420 & 2375 \\
\hline
\end{tabular}

Note: Various original cost data are converted to equivalent Euros for better comparison. The conversion rates are taken as: $1 €=1.20 €^{1}$ and $1 \$=0.75 €^{2}$.

Table 3. Costs of outage as experienced by different customer groups

It is quite difficult to make a general conclusion on financial losses in different industries as the PQ cost and the cost of outage due to interruption depend largely on the customer's installation characteristic and the devices involved. Among the industries, there can be a wide range of variety in device usages and their sensitivity to PQ problems. The same is also applicable for the commercial sectors.

\subsubsection{Estimation of financial losses caused by process failure}

When a disturbance occurs in an industrial process plant because of a voltage dip event, it can cause appreciable financial losses for the plant owner. The financial losses for an industrial customer can be determined as shown in equation (6) [Milanovic \& Jenkins, 2003].

$$
C L=M V-C M-C E+A C
$$

Where,
$\mathrm{CL} \quad=$ combined financial losses
MV = market value of goods that could be manufactured during the time of process outage. Also, called "opportunity lost: sales and profit forfeited".
$\mathrm{CM}=$ cost of material which could be used up in a production process
$\mathrm{CE} \quad=$ cost of energy that could be used up in a production process
AC = additional costs connected with a loss of supply

Alternatively, total financial losses because of a PQ event can also be expresses by equation (7). Both equations (6) and (7) are equivalent and any of it can be applied for calculating the financial losses due to voltage dips.

$$
C L=E E+(R L-V E) \cdot(r+s)+F C
$$

Where,

$\mathrm{EE}=$ extra expenses incurred because of the failure $(€ /$ per failure $)$

RL $\quad=$ revenue lost per hour of plant downtime $(€ /$ per hour $)$

$\mathrm{VE} \quad=$ variable expenses saved per hour of plant downtime $(€ /$ per hour $)$ 
$\mathrm{r} \quad=$ repair or replacement time after a failure (hours)

$\mathrm{s} \quad=$ plant start-up time after a failure (hours)

FC $\quad=$ any fixed costs $(€ /$ per failure $)$

Financial losses due to a voltage dip are very much influenced by the customer's load compositions and process layout at the plant site. Also, different base references are used in various case studies to represent voltage dip financial data (for example: sometimes the reference of representation is per event cost, sometimes per kVA or total installed capacity of the plant, and sometimes per hour cost or total cost in a year etc.). Fig. 10 provides a range of financial losses due to voltage dip event in different industries that can be used for macro-level planning purpose [Andersson \& Nilsson, 2002].

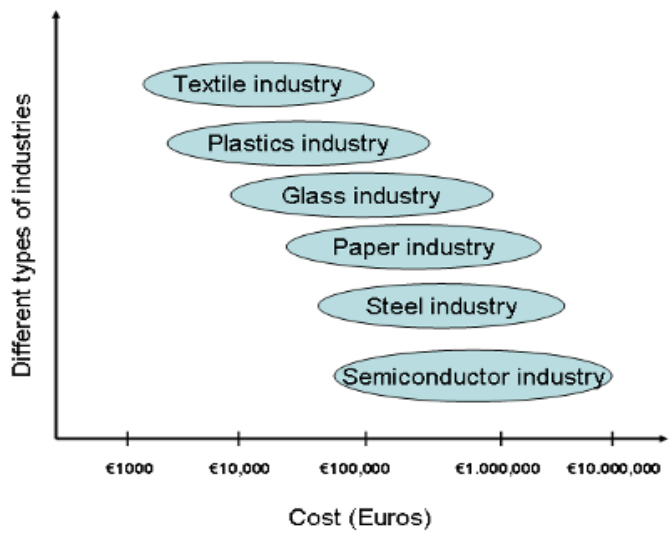

Fig. 10. Indicative financial losses in different sectors due to voltage dips

\subsubsection{Estimation of financial losses caused by harmonics}

Harmonic voltages and harmonic currents both can cause failure or abnormal operation of a customer's devices and can have financial consequences to the customer. Generally, harmonics in the network cause three types of problems:

- Additional energy losses (in the customer's transformers, connection cables, motors, neutral conductors etc.)

- Premature aging of a device

- Abnormal operation or misoperation of a device

Two methods can be applied to estimate costs related to harmonics: deterministic and probabilistic. The deterministic method is applied when all information related to the calculation (such as knowledge of network's operating conditions, various devices' operating conditions and absorbed power levels, the variation rate of the electrical energy unit cost and discount rate etc.) are available without any uncertainty. The present worth of operating costs of all components (represented as ' $(\mathrm{Dw})_{\mathrm{y}, \mathrm{pw}}$ ') in a considered installation for a period of $\mathrm{N}_{T}$ can be estimated as shown in equation (8) for a harmonic rich environment [Caramia et al., 2009].

$$
D w=\sum_{y=1}^{N_{T}}(D w)_{y, p w}=\sum_{y=1}^{N_{T}} \frac{(D w)_{y}}{(1+\alpha)^{y-1}}
$$


$(\mathrm{Dw})_{\mathrm{y}}$ is the sum of extra operating costs for all components (due to energy losses) at the customer's installation in all the time intervals for a specific year ' $y$ ' under consideration. ' $a$ ' is the present worth discount rate and $\mathrm{N}_{\mathrm{T}}$ is the period of years under consideration. Reference [Key \& Lai, 1996] gives estimation of harmonic related losses in office building. In this case, about $60 \mathrm{~kW}$ electronic loads (mainly computers) are connected that operates 12 hours per day for 365 days in a year. It was found from the analysis that those offices were paying extra energy bills of 2100 dollars each year (which is approximately $8 \%$ of the total energy bill) because of 21,9 MWh additional energy losses annually due to harmonics at the customer's installation. It was also observed that the station transformer became overloaded when supplying to only $50 \%$ of its capacity equivalent non-linear loads.

The premature aging caused by harmonic pollution involves incremental investment costs $\left(\mathrm{Da}_{\mathrm{k}}\right)$ for the $\mathrm{k}^{\text {th }}$ device during the observation period. This is shown by equation (9) [Caramia et al., 2009], where $\left(C_{k, n s}\right)_{\mathrm{pw}}$ and $\left(C_{k, s}\right)_{\mathrm{pw}}$ are the present worth values of total investment costs for buying the $\mathrm{k}^{\text {th }}$ device during its life in non-sinusoidal and sinusoidal operating conditions respectively.

$$
\left(D a_{k}\right)_{p w}=\left(C_{k, n s}\right)_{p w}-\left(C_{k, s}\right)_{p w}
$$

The evaluation of costs of misoperation is the most complex. It is often difficult to determine if the degradation of a device's performance is only due to harmonics or other PQ disturbances or due to other types of overloading. To estimate cost of a device's abnormal operation, it is required to get information of that device's characteristic under harmonic conditions, the activity for which the device is used and the relative importance of it in that process activity. Reference [Carpinelli et al., 1996] describes an investigation on a wide range of devices used in the commercial and industrial sectors and concluded that estimating the cost of abnormal operation requires extensive information on a device's behaviour in the presence of harmonics, the activity in which the device is used and the economic values of all items contributing to lower productivity.

Most of the cases it is difficult to gather all information related to costs as harmonics have mainly long term impacts and have relatively less visual immediate effects. Therefore, probabilistic method of cost estimation can also be applied when some of the calculating parameters are uncertain or not known correctly. Equation (10) shows a general equation to estimate the expected economical value of present worth of harmonics '(D) $)_{\mathrm{pw}}$ ' for a device in the probabilistic analysis [Caramia et al., 2009]. It includes a probability density function ' $E$ ' which describes its statistical feature of failure probability of the device, '(Dw $)_{\mathrm{pw}}$ ' represents present worth of additional energy losses and ' $(\mathrm{Da})_{\mathrm{pw}}$ ' is the present worth of incremental investment due to premature aging of the device.

$$
E(D)_{p w}=E(D w)_{p w}+E(D a)_{p w}
$$

\subsubsection{Consequences of voltage flicker}

Voltage flicker is an annoying problem for the customers. Most of the times, it does not have high financial impact. However, it causes inconveniences to the people when frequent flickering (of light and computer screens) occurs at their work-places or homes. From field studies it was found that voltage flicker can cause severe headache, epilepsy and other vision related illness to the customers. So, the affected people have to go for medical supervisions that might involve appreciable expenses. It was estimated from the LPQI 
survey [Manson \& Targosz, 2008] that the cost consequences due to flicker related problems can be up to $10 \%$ percent of an organization's employment costs.

\subsection{PQ costs for the network operators}

Poor PQ has impacts to the network components (such as cables, transformers, capacitor banks etc.) that might suffer excessive heating, overloading, reduced energy efficiency, undesired tripping and early aging. Not many case studies are done yet to estimate the financial impacts of poor PQ for network components. However, it is clear that the network operators experience additional losses in the networks because of harmonic currents, mostly originated by various customers' devices. Also, the costs of unwanted tripping of protective devices or control equipments in the network can be significant as those can lead to unplanned supply interruption. The cost of reduced equipment's lifetime due to early aging is also very high, especially for expensive network devices. A transformer is expected to have a lifetime of at least 30-40 years. It is possible that it has to be replaced in 10 years earlier due to its early aging caused by increased harmonic pollutions in the network. Most of the time, the effects of harmonics are hidden and not immediately visible.

Light flicker is another PQ problem that has drawn high attention even though it has lesser financial impacts than harmonics and voltage dip problems. It can cause bad reputation of the network operator as a service provider in the electricity business. Also, when a customer complaints to the network operator about flicker problem, then an inspection engineer has to be sent to the site to supervise the problem to take necessary action. All these cause extra cost for the network operator.

In an existing network, $\mathrm{PQ}$ performance can be improved by rearranging and reinforcing the network. Also, regular maintenance strategy has to be adopted to enhance the lifetime of the network components and reduce failure rate. All these require appreciable investments. Implementing a mitigation device is another method to increase PQ performance level in the network at a desired level. The decision on adapting one of those strategies can be done after carefully analyzing PQ problem experienced by the network operators and customers and their relative financial losses in comparison to the investment required. Furthermore, it is also possible to tighten the PQ (or EMC) standards for the equipments so that they become less sensitive to disturbances. This requires a regulatory change and also can increase the equipment's manufacturing cost.

\subsubsection{Harmonics in the network}

At present, no published case study shows that the network components are failing because of poor PQ. However, it is often found that extra losses are occurring in the network components because of additional harmonic currents in the network. In the future electricity infrastructure, with the increased usage of many power electronics devices, harmonics can become a problem in the networks. Regular PQ monitoring can probably indicate actual PQ situation in the network. Various costs of harmonics are categorised as the operating cost (e.g. increased power losses), the aging cost (e.g. reduced lifetime cost) and the cost due to equipment's maloperation. All those costs can be calculated by the same method as described in section 4.1.2. When large harmonic currents flow in a network, the network operators often can notice its impacts immediately as the network components get overloaded. In extreme situation, it can cause tripping of the protection device. Reference [Papathanassiou et al., 2007] estimates an increase of only around $0.15 \%-0.20 \%$ of the total 
losses in the network components (lines and transformers) because of existing level of harmonics in the Greek networks.

\subsubsection{Consequences of voltage dips}

A voltage dip event can disrupt the operation of sensitive devices that might lead to partial or complete interruption of a customer's power supply. The effects of voltage dips mainly depend on the type of customer, the usage of the power supply and the electricity demand of the installation. Fig. 11 shows the EPRI-PEAC survey [McNulty et al., 2002] results of the US industrial customers (mainly continuous manufacturing process industries and digital economy sectors). It shows that different durations of outages at the customer's installations can have varying impacts to them. For a $1 \mathrm{sec}$ of power failure (or very deep voltage dip), around $56 \%$ of the total surveyed industrial customers suffer process interruptions of 1.1-30 min at their installations, while $27 \%$ customers suffer a sudden outage at their sites for a duration of 1 minute or less. Similarly, when the supply power failure is for 3 minutes, it was noticed that around $82 \%$ of the surveyed customers would face a process interruption in the range of 1.1-30 minutes and 15\% of them experience process outages for 30 minutes to 2 hours. In this survey, it was estimated that for an industrial customer the average process outage time after 1 second power supply failure is 21 minutes. However, it is only an indicative value. The real process outage time can vary largely among different industries depending on their type of operations and sizes.

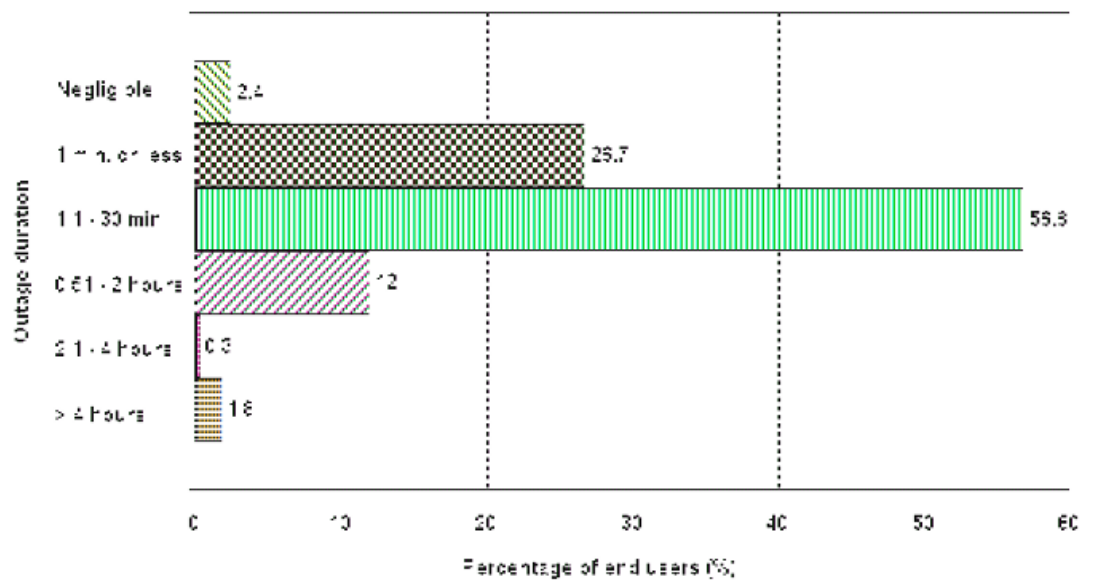

Fig. 11. Outage durations in different industries for $1 \mathrm{sec}$ power failure

Generally, the industrial customers demand large quantities of electricity. Therefore, when a voltage dip event in the network disrupts the power supply of many industries in a specific part of the network, it can have significant financial impacts to the concerned electricity service providers (due to loss of 'kWh units' of electricity tariff).

\section{Other impacts of poor $P Q$}

Another aspect that has grown interest in the electricity service sector is the 'customer satisfaction' index. It depends mainly on the mutual relationships between a customer and 
network operator; and indicates the commercial quality of the electricity distribution service. Commercial quality generally relates to the individual agreement between network operator and customer. However, only some of these relations can be measured and regulated through standards or other legal instruments. When more customers are not satisfied with the PQ of the supply, the network operator may lose the trust of the customers. In the extreme situation, the national regulators may take action against the network operator to solve the problem. Presently, in many countries the network operators are obliged to verify PQ complaints of individual customers. They should provide a voltage at a customer's terminal that has to fulfil the applicable standard requirements. However, a customer's responsibility regarding various $\mathrm{PQ}$ requirements at the point of connection is not yet well defined. Therefore, it is a challenge for the network operator to maintain both the technical and service quality to satisfy the customers' needs.

When a customer buys a product from the market, the 'brand name' plays an important role in decision making of his purchase. A device when is sold in the market, the device manufacturer guarantees its performance as per the relevant product standards (of IEC or other internationally recognized standard) under clean voltage condition. However, in reality, the devices operate in an electricity environment with distorted supply voltage. Thus, the connected devices generate different harmonic currents than that at sinusoidal voltage condition. In certain situations, some specific order harmonic current can exceed the limits of the standards. Also, it produces extra losses and may operate abnormally that leads to the decrement of its lifetime. All these can bring doubts in the customer's mind about the quality of the device and indirectly on the device manufacturers supplied product's quality. Thus, the 'commercial quality' of the equipment manufacturer might get affected too.

\section{Responsibility sharing among various parties}

Many PQ problems in the network are contributed by customer's nonlinear devices and most of those devices are susceptible to failures under polluted supply voltage condition. In addition, some PQ problems such as voltage dips, transients are mainly originated in the network side. Improving a network to reduce PQ problem costs huge amount of investment for a network operator; while poor PQ also accounts large financial losses to the customers. Therefore, following parameters have to be considered for PQ cost analysis in the networks:

- Network's mitigation cost (such as changes in network infrastructure, placing a PQ mitigation device etc.)

- Compensation for the extra losses in network components

- Extra costs to handle customer's complaints (effort in finding the problem, network intervention for modification and improvement)

- Customer's willingness to pay extra money (and tariff) to minimize PQ disturbances at their installations

- Evaluation of cost of extra-quality by introducing individual 'PQ contract' scheme

- Costs aspects that concern manufacturers in designing equipment for improving PQ (emission and immunity of equipment)

- Total market size (that means the number of customers involved) for a specific PQ solution under consideration

To implement PQ mitigation, it is required to evaluate different alternatives to improve PQ performance in the network. Therefore, a systematic approach is followed to first find out the responsibility of each of the involved parties in the network as shown in Fig. 12. 


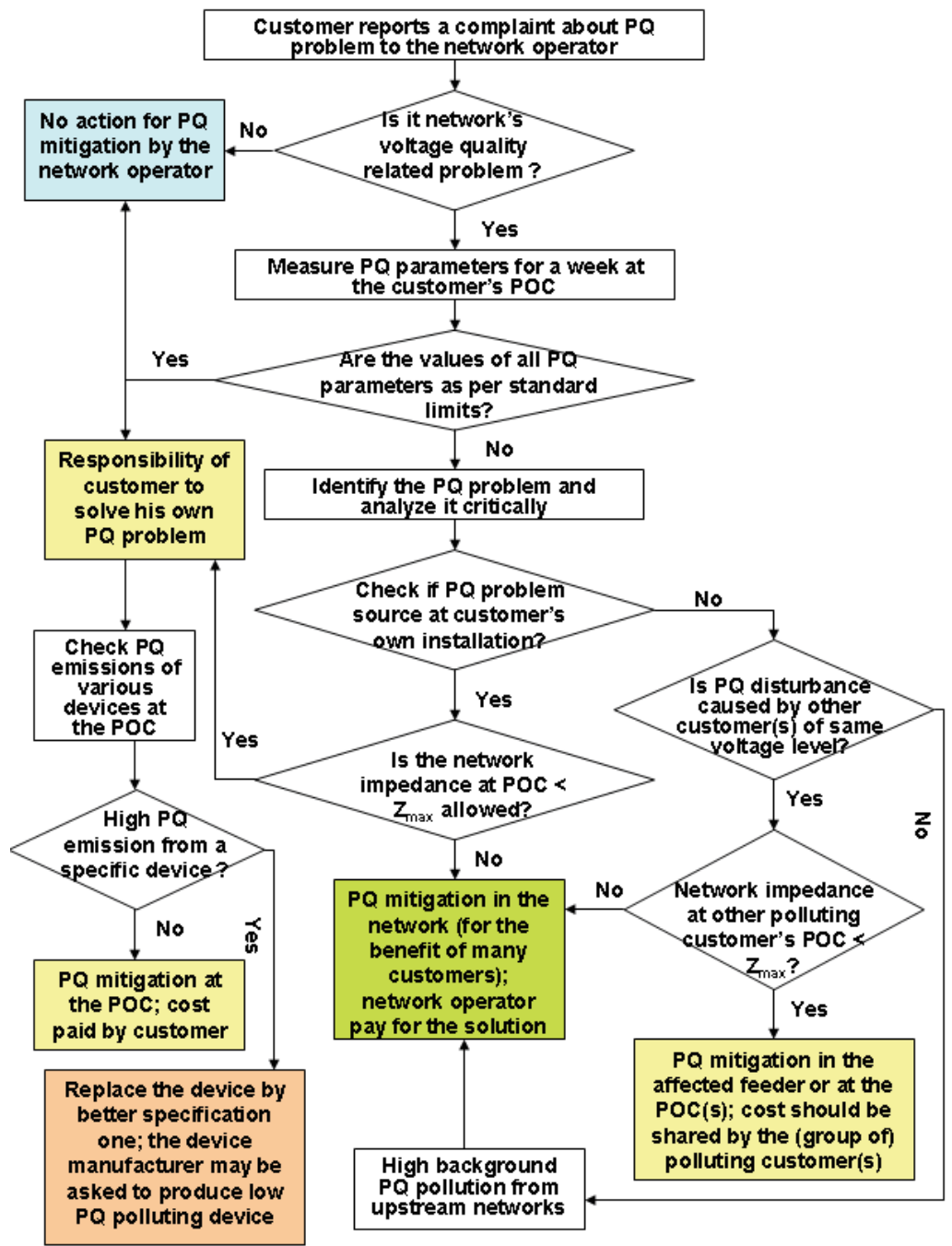

Fig. 12. Decision making flow-chart on PQ solutions

One of the main influencing factors on the decision making is the number of complaints that a network operator gets from the customers because of poor PQ of the supply. First, the source of $P Q$ problem in the network is to be detected. It is also important to know about the network impedance at the POC where customer is facing PQ related inconveniences. After analysing the problem, network operator may ask the customer either to install a mitigation device at his terminal or to pay for the solution, if the problem is caused by the customer's device. On contrary, if the network impedance at POC is found higher than the maximum (fundamental and harmonic) impedance allowed for the customer's connection type, the network operator will be responsible to solve the PQ problem. Depending on the sensitivity of the problem, the network operator has to implement mitigation method at the 
complaining customer's POC, or in the feeder or elsewhere in the network to fulfil the needs of a large group of customers. Thus, following situations are possible while deciding on an investment for a PQ solution:

- A mitigation method is chosen at the customer's terminal or in his installation and the investment is also done by the customer.

- Mitigation method is adopted at the customer side, but the investment is done by the network operator.

- A mitigation method can be implemented in the network (such as: network a reconfiguration, laying an extra cable, installing storage or filters, etc.) while the investment can be shared by the network operator and the customer, depending on the situation.

Finding an optimal PQ solution and defining PQ related responsibility of each of the parties connected in the network are complicated issues. The standards that are presently available give limiting values for some specific PQ parameters that are valid only for sinusoidal voltage condition. Hence, the standards also need to be adjusted to restrict PQ emissions at a customer's installation. Alternatively, various devices can be manufactured with stricter specification so that they produce less PQ pollution in the network. Moreover, all the concerned parties would work together to find out the best solution. Fig. 13 illustrates mutual responsibility sharing on PQ aspects among the network operator, the customer and the equipment manufacturer.

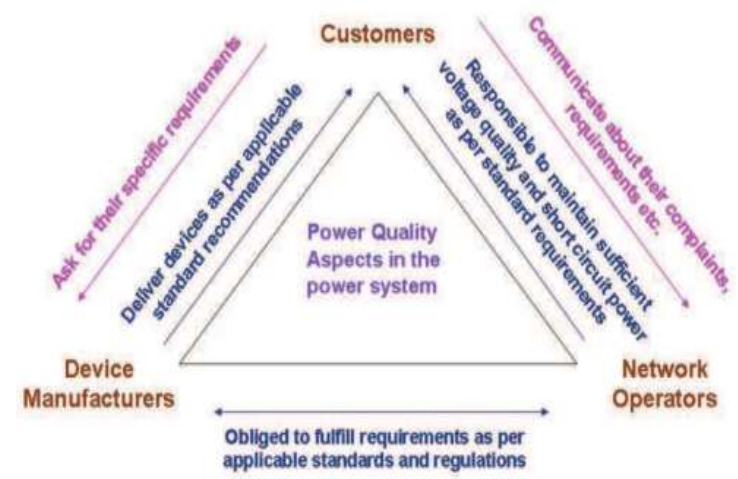

Fig. 13. Mutual responsibilities among various parties in the network

\section{Conclusion}

Poor PQ causes techno-economic inconveniences to different parties connected to the network. PQ problems such as voltage dips and harmonics can have significant technoeconomic impacts to the customers and the network operators. It was found from the LPQI survey (2004) in the EU-25 countries that electronic equipments, electrical motors, variable speed drives and static converters are the most affected equipments in the industries. The other affected devices are cables, capacitors, lighting equipments and relay contactors. Estimating the financial losses for a customer because of poor PQ is quite complicated as it includes various direct (immediately visible costs) and indirect (long-term) costs. The methodologies for calculating the costs related to voltage dips and harmonics are described 
in this chapter. It was found that continuous manufacturing process plants and digital industries are the most vulnerable sectors for PQ related disturbances. It was also noticed that the network operators can have significant inconveniences too because of poor PQ in the network. Network components suffer extra losses, reduced operational efficiency, abnormal tripping and premature failure because of harmonics in the network. Various reference case studies are mentioned where poor PQ related financial losses for the customers and network operators have occurred. It was found that light flicker is technically not a big problem for the network. However, when the customers suffer from flicker related disturbances and complain frequently to the network operators, it can have some financial consequences. The 'commercial quality' aspect of the electricity is also briefly discussed that emphasizes on the customer's satisfaction about the received electricity.

The presence of polluting devices in the network often distorts the supply voltage. Under a polluted grid condition, a customer's devices behave differently than the sinusoidal voltage condition. The present standards give requirements on PQ parameters only for clean sinusoidal voltage condition. In future, those standards need to be modified to make them more appropriate for the real distorted network voltage condition. Also, the standards should specify clearly the responsibility of the customer regarding various PQ parameters at the connection point of his installation with the network. To select an optimum PQ mitigation method in the network, a detailed cost-benefit analysis is to be done for the involved parties.

\section{References}

Andersson, T.; \& Nilsson, D. (2002). Test and evaluation of voltage dip immunity. STRI AB and Vatenfall $A B$ 27, November 2002.

Bhattacharyya, S.; Cobben, S.; \& Kling, W. (2010). Harmonic current pollution in a low voltage network, Presented as a panel list paper in IEEE PES GM 2010 conference, July 2010, Minnesota.

Caramia, P.; Carpinelli, G.; \& Verde, P. (2009). Power quality indices in liberalized markets. A John Wiley \& Sons Ltd., ISBN: 978-470-03395-1.

Carpinelli, G.; Caramia, P.; Vito, E. Di.; Losi, A.; \& Verde, P. (1996). Probabilistic Evaluation of the Economical Damage due to Harmonic Losses in Industrial Energy System. IEEE Transactions on Power Delivery, vol. 11, No. 2. April 1996.

CEER (2008). 4 $4^{\text {th }}$ Benchmarking report on quality of electricity supply 2008. Issued by: Council of European Regulators ASBL, Brussels, December 2008. Ref.: C08-EQS-2404.

Cobben, S.; Kling, W.; \& Myrzik, J. (2007). The making and purpose of harmonic fingerprints. Proceeding of $19^{\text {th }}$ International Conference on Electricity Distribution (CIRED 2007). Vienna.

Desmet, J.; Putman, D.; D'hulster, F.; Belmans, R. (2003). Thermal analysis of the influence of nonlinear, unbalanced and asymmetric loads on current conducting capacity of LVcables. Proceeding of IEEE Bologna PowerTech conference, Bologna, Italy, June 2003.

Emanuel, A. E.; McNeil, J. A. (1997). Electric power quality, Annual Rev. Energy Environ, Worcester Polytechnic Institute, Massachusetts, USA. Ref no. 1997.22:263-303.

Fuchs, E.F.; Roesler, D.J.; \& and Kovacs, K.P. (1986). Aging of electrical appliances due to harmonics of the power system's voltage. IEEE Transactions on Power Delivery, Vol. PWRD-1, no. 3, July 1986. 
Hulshorst, W.T.J.; Groeman, J.F. (2002). Energy saving in industrial distribution transformers. KEMA report, reference 40130017-TDC 02-24226A.

Johnson, P.; Coney, R. (1997). Introducing national quality of supply (power quality) standards the South African experience. 10 In International Conference on Electromagnetic Compatibility, Conference, publication no. 4450 IEE 1997, September 1997.

Kariuki, K.K.; Allan, R.N. (1996). Evaluation of reliability worth and value of lost load. IEE proceedings: General Transmission and Distribution, vol. 143.

Keulenaer, H. De. (2003). The hidden cost of poor power quality, Leonardo Energy, European Copper Institute, October 2003. Available: www.leonaro-energy.org

Key, T.S.; \& Lai, J.S. (1996). Costs and benefits of harmonic current reduction for switchmode power supplies in a commercial office building. IEEE Transactions on Industry Applications, vol. 32, no. 5.

Lineweber, D. ; McNulty, S.R. (2001). The cost of power disturbances to industrial \& digital economy companies, EPRI IntelliGrid Initiative (A Primen report from EPRI \& CEIDS), Ref no. 1006274, June 2001. Available : www.epri.com/ceids

Targosz, R.; Manson, J. (2007). PAN European LPQI power quality survey, Proceedings of 19th International Conference on Electricity Distribution (CIRED 2007), May 2007, Vienna.

Manson, J.; Targosz, R. (2008). European power quality survey report Leonardo Energy, November 2008, www.leonardo-energy.org.

McNulty, S.; Primen; \& Howe, B. (2002). Power quality problems and renewable energy solutions. Submitted to Massachusetts Renewable Energy Trust, September 2002.

Melhorn, C.J.; Maitra, A.; Sunderman, W.; Waclawiak, M.; Sundaram, A. (2005). Distribution system power quality assessment phase-II: voltage sag and interruption analysis. Copyright IEEE, paper no. PCIC- 2005-13.

Milanovic, J.V.; Jenkins, N. (2003). Power quality cost for manufacturing industries. Presented on EDF workshop in Paris, Paris.

Najdenkoski, K.; Rafajlovski, G.; \& Dimcev, V. (2007). Thermal aging of distribution transformers according to IEEE and IEC standards. Power Engineering Society General Meeting, 2007, IEEE, ISBN: 1-4244-1296-X.

Papathanassiou, S.; Kasmas, N.; Drossos, N.; Stavropoulos, D. (2007). A practical evaluation of distribution network losses due to harmonics. Proceeding of 19th International Conference on Electricity Distribution (CIRED 2007), Vienna, June 2007.

Wharmby, B. (1998). Power quality in the privatised UK electricity industry. Proceedings of Industry Applications Conference, at 33rd IAS annual meeting, volume: 3, pp: 22882291, 1998. 


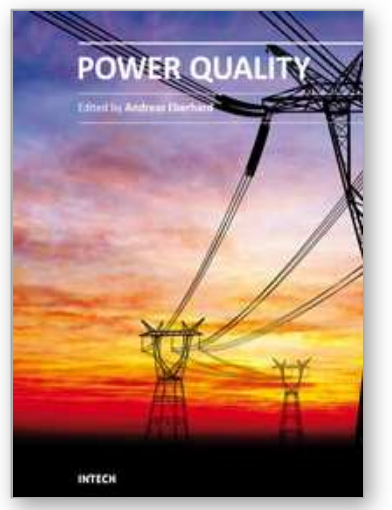

\author{
Power Quality \\ Edited by Mr Andreas Eberhard
}

ISBN 978-953-307-180-0

Hard cover, 362 pages

Publisher InTech

Published online 11, April, 2011

Published in print edition April, 2011

Almost all experts are in agreement - although we will see an improvement in metering and control of the power flow, Power Quality will suffer. This book will give an overview of how power quality might impact our lives today and tomorrow, introduce new ways to monitor power quality and inform us about interesting possibilities to mitigate power quality problems.

\title{
How to reference
}

In order to correctly reference this scholarly work, feel free to copy and paste the following:

Sharmistha Bhattacharyya and Sjef Cobben (2011). Consequences of Poor Power Quality - An Overview, Power Quality, Mr Andreas Eberhard (Ed.), ISBN: 978-953-307-180-0, InTech, Available from: http://www.intechopen.com/books/power-quality/consequences-of-poor-power-quality-an-overview

\section{INTECH}

open science | open minds

\section{InTech Europe}

University Campus STeP Ri

Slavka Krautzeka 83/A

51000 Rijeka, Croatia

Phone: +385 (51) 770447

Fax: +385 (51) 686166

www.intechopen.com

\section{InTech China}

Unit 405, Office Block, Hotel Equatorial Shanghai

No.65, Yan An Road (West), Shanghai, 200040, China 中国上海市延安西路65号上海国际贵都大饭店办公楼 405 单元

Phone: +86-21-62489820

Fax: $+86-21-62489821$ 
(C) 2011 The Author(s). Licensee IntechOpen. This chapter is distributed under the terms of the Creative Commons Attribution-NonCommercialShareAlike-3.0 License, which permits use, distribution and reproduction for non-commercial purposes, provided the original is properly cited and derivative works building on this content are distributed under the same license. 